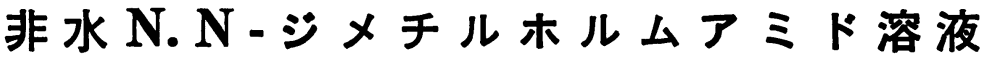 よりの金属の析出
}

\section{Electrodeposition of Metals from Non-aqueous N, N-dimethyl Formamide Solutions}

馬場宣良*・竹内幸夫*・森崎重喜*

Nobuyoshi BABA Yukio TAKEUCHI and Shigeyoshi MORISAKI

Electrodeposition of metals (such as $\mathrm{Ag}, \mathrm{Bi}, \mathrm{Cd}, \mathrm{Co}, \mathrm{Cu}, \mathrm{Ni}, \mathrm{Pb}, \mathrm{Pd}, \mathrm{Pt}$, and $\mathrm{Zn}$ ) from nonaqueous DMF solutions saturated with the corresponding metal salts was investigated lunder steadystate current with no agitation.

Crystals having regular dendritic structure were formed in cases of $\mathrm{Co}, \mathrm{Ni}, \mathrm{Pb}$, and $\mathrm{Zn}$ under current density of $10 \sim 64 \mathrm{mAmp} / \mathrm{cm}^{2}$. Whereas, less crystalline or amorphous deposits were obtained in case of $\mathrm{Pt}$.

The deposits of $\mathrm{Bi}, \mathrm{Cd}, \mathrm{Cu}$, and $\mathrm{Pd}$ were grown up into dendritic or mossy structure, according to the current density.

The growth of the dendritic structure was controlled by the following factors :

1. Current density and exchange current density

2. Ion concentration

3. Ionic conductivity

The leading factors for promoting the growth of dendritic structure in D.M.F. solutions were low exchange current density and low ionic conductivity.

\section{1. 緒 言}

水溶液からの金属の電析に関する研究は多いが，非水 溶液からの金属の電析については古くからいろいろ試み られていたにるかかわらず1), 2), 高価な溶媒と複雑で注 意深い操作を必要とするわりには，電析物の性質に水溶 液より得られるものより特别な利点がないため，ほとん そ不成功に終っている。そのなかで Brenner ${ }^{3}$ らの一 連の研究は水溶液中では通常析出しないといわれてい る, マグネシウム, アルミニウム, ホウ素などの単独ま たは合金電析を得たと報告されているので，これは非水 溶液を用いる金属電析に関する数少ない成功例といえよ ら。林らの総説4),5)によれば, 非水溶液よりの金属の電 析のらち，工業的に利用されらる程度まで研究されたも のはアルミニウムしかなく，それ以外の金属については いまだ基礎的研究のデータに乏しいので, 電解槽内の反 応 (電極反応, 結晶成長機構など) その子のについて不 明な点が多いのが現状のようである。そこで本実験にお いては, これまでの研究者達によっていまだ試みられて いない, N. N-ジメチルホルムアミド (以後DMFと略 称する）を溶媒として，いろいろな金属について電析を

* 東京都立大学工学部 (東京都世田谷区梁沢 2-1-1)

Tokyo Metropolitan University
試みたところ，銅，銀，カドミウムなどは水溶液系と同 じようにデンドライトの成長がみられたが，このほかに 水溶液系ではきわめて高濃度, 高温度, 高電流密度飞お いてしか得られなかったニッケル，コバルトの樹枝状成 長注1) が常温, 通常の電流密度 $\left(10 \sim 200 \mathrm{~mA} / \mathrm{cm}^{2}\right)$ 条 件で得られたのであわせて報告する。ここで用いた DM Fは誘電率はかなり高く（約 37）, 活性水素をるたない いわゆる polar aprotic solvent であるので，金属析 出時の水素の同時発生といら競争反応の心配がないの できわめて卑な金属の析出にも有利であるように思わ れる。

\section{2. 実 倹}

\section{2-1 溶媒の精製}

第 1 表 DMFの物理定数

\begin{tabular}{|c|c|c|}
\hline 融 & 点 & $-61^{\circ} \mathrm{C}$ \\
\hline \multirow{2}{*}{$\begin{array}{l}\text { 沸 } \\
\text { 双極モ—xン } \\
\mathrm{D}\left(25^{\circ}\right)^{\alpha}\end{array}$} & 点 & $153^{\circ} \mathrm{C}$ \\
\hline & 卜 & $3.86 \pm 0.01$ \\
\hline 誘 電 恒 & 数 & $26.6\left(25^{\circ} \mathrm{C}\right)$ \\
\hline 粘 & 度 & 0.802 \\
\hline 密 & 度 & $0.9445\left(25^{\circ} / 4^{\circ} \mathrm{C}\right)$ \\
\hline
\end{tabular}

注 1）単結晶が樹枝状に成長するものをデンドライトと 称し，形態のみ樹枝状のものと区別して用いた。 


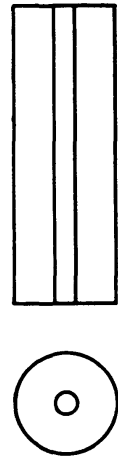

(a) 作用電糧

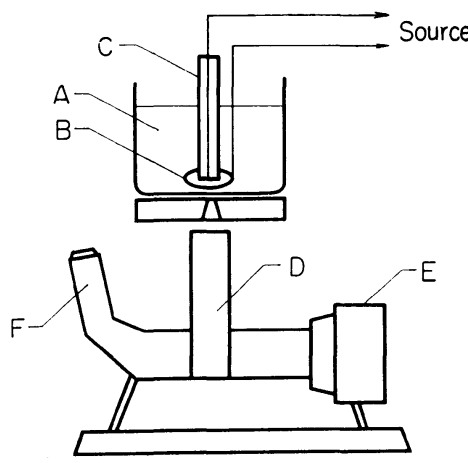

(b) 䡠微鏡観察装置

$$
\begin{aligned}
& \mathrm{A} \text { : 電解液 } \mathrm{B}: \text { アノート } \mathrm{C}: \text { カ カード } \\
& \mathrm{D}: \text { 金属顕徽 } \mathrm{E}: \text { カメラ } \mathrm{F}: \text { ファインダー } \\
& \text { 第1园実 験 装 圆 }
\end{aligned}
$$

市販のDM F (99.9\%)に酸化バリウムの粉末を加え， 時々かきまぜながら $24 \mathrm{~h}$ 放置する。次に減圧蒸留フラス コに移し, $10 \sim 20 \mathrm{mmHg}$ の減圧下で $80 \sim 100^{\circ} \mathrm{C}$ の温 度で蒸留し，その留分のうち中央部のみを集める ${ }^{6)}$ 。得 られた溶媒の比電導度は $1.89 \times 10^{-6} \Omega^{-1} \mathrm{~cm}^{-1}$ であっ た。

\section{第 1 表にDMFの溶媒としての諸性質を示す。}

\section{2-2 溶}

試みた電解質は無水の特級試薬を用い，とくに再結晶 などの精製は行なわなかった。非水といら条件から結晶 水を含む塩は一度 DMF に溶解し，再結晶させて溶媒和 した塩に変えてから使用した。

無水または溶媒和された塩の形の制限から次のものが 実験に用いられた。

$\mathrm{AgNO}_{3}, \mathrm{BiCl}_{3}, \mathrm{CuSO}_{4}, \mathrm{~Pb}\left(\mathrm{NO}_{3}\right)_{2}, \mathrm{PdCl}_{2}, \mathrm{ZnCl}_{2}$, $\mathrm{H}_{2} \mathrm{PtCl}_{6}, \mathrm{CdCl}_{2} \cdot 2 \mathrm{DMF}, \mathrm{CoCl}_{2} \cdot 2 \mathrm{DMF}, \mathrm{NiCl}_{2}$. n DMF

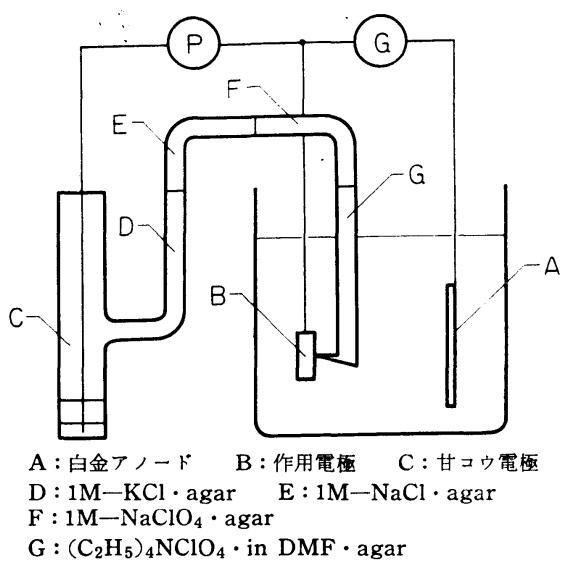

第2图分極測定装置

電解液の濃度はできるだけ濃厚なるのを用いた（第 2 表参照)。

\section{2-3 実験装置}

非水溶液電解の実験は全密閉方式で行ならべきである が，本実験に打いては電析物の状態を連続的に観察する 都合上，完全密閉式とすることができなかったので，や むなく空気開放下に打いて実験を行なった。カソードは 第 1 図の(a)のように白金線をパイレックスガラス管に封 入したもので，その断面積は $0.78 \mathrm{~mm}^{2}$ である。アノー ドには白金板を第 1 図の(a)のように配置し，カソード上 への電析の状態が電解槽の下面から顕微鏡によって観察 できるようになっている。分極の測定には定常法を用い た。電解セルの構造は第2図に示してある。DMF溶媒 中の基準電極はいまだ知られていないので，種々の予備 実験を行なった結果, 次のような電池の構成で安定な電 位を得ることができた。

$\mathrm{SCE}(\mathrm{aq}) \cdot \mathrm{KCl}$ (Sat.) $\cdot \mathrm{KCl}(1 \mathrm{M})$ agar $\cdot \mathrm{NaCl}(1 \mathrm{M})$

agar $\cdot \mathrm{NaClO}_{4}(1 \mathrm{M})$ agar $\cdot\left(\mathrm{C}_{2} \mathrm{H}_{5}\right)_{4} \mathrm{NClO}_{4}$ agar in DMF

この半電池は製作後約

第 2 表 用いた電解液の比電導度および当量電導度

\begin{tabular}{l|c|c|c}
\hline \multicolumn{1}{c|}{ 塩 } & 濃度 $\mathrm{mol}$ & 比電導度 $\mathrm{ohm}^{-1} \mathrm{~cm}^{-1}$ & 当量電導度 $\mathrm{ohm}^{-1} \mathrm{~cm}^{2}$ \\
\hline $\mathrm{CoCl}_{2} \cdot 2 \mathrm{DMF}$ & 0.68 & $3.19 \times 10^{-3}$ & - \\
$\mathrm{CdCl}_{2} \cdot 2 \mathrm{DMF}$ & Sat. & $9.45 \times 10^{-4}$ & - \\
$\mathrm{NiCl}_{2} \cdot \mathrm{nDMF}$ & & $3.78 \times 10^{-3}$ & - \\
$\mathrm{ZnCl}_{2}$ & Sat. & $5.26 \times 10^{-3}$ & - \\
${\mathrm{Pb}\left(\mathrm{NO}_{3}\right)_{2}}_{\mathrm{BiCl}_{3}}$ & 0.31 & $1.23 \times 10^{-3}$ & 1.98 \\
$\mathrm{CuSO}_{4}$ & 0.32 & $6.05 \times 10^{-4}$ & 0.63 \\
$\mathrm{AgNO}_{3}$ & Sat. & $1.73 \times 10^{-5}$ & - \\
$\mathrm{PdCl}_{2}$ & 0.60 & $2.84 \times 10^{-3}$ & 4.72 \\
$\mathrm{H}_{2} \mathrm{PtCl}_{6}$ & Sat. & $4.52 \times 10^{-5}$ & - \\
\hline \hline
\end{tabular}
40日経過すると, 電位の 変動がなくなり, その後 安定な電位を示し続ける ことが確認された（第3 図)。この分極測定の際 にはカソードとして 10 $\mathrm{mm} \times 10 \mathrm{~mm}$ の被测定金 属板を用い，対極は白金 板を用いた。分極電位の 測定にはポテンシオメー ターを使用した。 


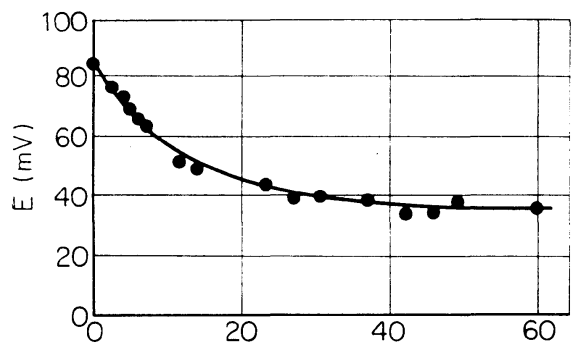

時 間 (day)

第3図 $\operatorname{SCE}$ (non-aquous) と $\operatorname{SCE}$ (aq.) と を組み合わせたときの電位の経時変化

\section{3. 結果および考察}

（1）常に樹枝状に発達するるの（結晶性） コバルト, ニッケル, 亜鉛, 鉛, 銀

(2) コロイド状に析出するもの 白金

(3) 電流密度によって析出形態がいろいろ变化するも の

銅, カドミウム, ビスマス, パラジウム

(1)に属するものは実験された全電流密度の範囲にわた って樹枝状に析出するもので, 樹枝状に発達する枝は電 流密度の増大とともに細い針状となる（写真1の a , b), とくにニッケル, コバルトの樹枝状析出の電流密 度を, 水溶液系よりの樹枝状析出の場合之比べてみる と 7,8) 著しく低い。たとえばニッケルは $\mathrm{NiCl}_{2}$ の濃厚な 沸騰溶液から $5 \mathrm{~A} / \mathrm{cm}^{2}$ の電流密度で樹枝状析出となる

\section{3-1 溶液の比里筫度および当 量電等度}

第 2 表に用いた電解液の比電導 度および，濃度既知のものについ ては当量電導度が計算してある。 ほぼ同じ濃度の水溶液の場合と比 較すると 1/10 以下である。 D MFの粘度は 0.802C P でこれは 水のそれとほとんど変わりないの で, 塩のDMF中での電導度の低 下は粘度のためではなく注2), 解 離そのものが少ないためであるこ とがわかる。

\section{3-2 電析物の顕微鏡的観察}

種々の電流密度で金属塩の溶液 を電解し，そのカソード析出物の 外観を第3 表にまとめて示して ある。顕微鏡観察のため，すべて の場合析出物は明るい視野の中に 黒色不透明体として観察された。 析出物の外観は大きく分けて次の 3つの場合がある。

注 2) Walden の法則によれば, 同じ塩を種々の溶媒に溶か したとき，その溶媒の粘度 と無限希釈に和ける当量電 導度との間には次の関係が ある。 $\eta_{1}{ }^{0} \cdot \lambda_{1}{ }^{0}=\eta_{2}{ }^{0} \cdot \lambda_{2}{ }^{0}$ この場合 $\eta_{1}{ }^{0} \approx \eta_{2}{ }^{0}$ である から $\lambda_{1}{ }^{0} \approx \lambda_{2}{ }^{0}$ となるはず である。
第 3 表 電 析 物 の 外 観

\begin{tabular}{|c|c|c|c|c|}
\hline 溶 & $\begin{array}{l}\text { 濃 } \\
\mathrm{mol} / l \times 10\end{array}$ & $\begin{array}{l}\text { 電流密度 } \\
\mathrm{mA} / \mathrm{cm}^{2}\end{array}$ & 浴電压 & 電析形状, 色 \\
\hline $\mathrm{CdCl}_{2} \cdot 2 \mathrm{DMF}$ & Sat. & $\begin{array}{c}0.64 \\
2.6 \\
25.0\end{array}$ & $\begin{array}{r}7.0 \\
9.0 \\
21.5\end{array}$ & $\begin{array}{l}\text { こけ状, 黒 } \\
\text { 樹枝状, 黒 } \\
\text { こぶ状, 黒 }\end{array}$ \\
\hline $\mathrm{NiCl}_{2} \cdot \mathrm{nDMF}$ & & $\begin{array}{r}6.4 \\
10.0 \\
25.0\end{array}$ & $\begin{array}{r}4.0 \\
6.0 \\
19.0\end{array}$ & $\begin{array}{l}\text { 樹枝状, 黒 } \\
\text { 樹枝状, 黒 } \\
\text { 樹枝状, 黑 }\end{array}$ \\
\hline $\mathrm{CoCl}_{2} \cdot 2 \mathrm{DMF}$ & 0.68 & $\begin{array}{r}6.4 \\
13.0 \\
64.0\end{array}$ & $\begin{array}{l}5.1 \\
7.4 \\
5.0\end{array}$ & $\begin{array}{l}\text { 樹枝状, 黒 } \\
\text { 樹枝状, 黒 } \\
\text { 樹枝状, 黒 }\end{array}$ \\
\hline $\mathrm{Pb}\left(\mathrm{NO}_{3}\right)_{2}$ & 0.31 & $\begin{array}{r}6.4 \\
13.0 \\
38.0\end{array}$ & $\begin{array}{l}3.7 \\
3.0 \\
9.0\end{array}$ & $\begin{array}{l}\text { 樹枝状, 黒 } \\
\text { 樹枝状, 黒 } \\
\text { 樹枝状, 黒 }\end{array}$ \\
\hline $\mathrm{CuSO}_{4}$ & Sat. & $\begin{array}{r}1.3 \\
6.4 \\
13.0\end{array}$ & $\begin{array}{l}200 \\
260 \\
200\end{array}$ & $\begin{array}{l}\text { 樹枝状, 黒 } \\
\text { 樹枝状, 黑 } \\
\text { 樹枝状, 黒 }\end{array}$ \\
\hline $\mathrm{AgNO}_{3}$ & 0.60 & $\begin{array}{r}6.4 \\
13.0 \\
38.0\end{array}$ & $\begin{array}{l}1.1 \\
1.5 \\
3.1\end{array}$ & $\begin{array}{l}\text { 樹枝状, 黒 } \\
\text { 樹枝状, 黑 } \\
\text { 樹枝状, 黒 }\end{array}$ \\
\hline $\mathrm{PdCl}_{2}$ & Sat. & $\begin{array}{r}1.3 \\
6.4 \\
13.0\end{array}$ & $\begin{array}{l}34 \\
34 \\
40\end{array}$ & $\begin{array}{l}\text { 樹枝状, 黒 } \\
\text { 樹枝状, 黒 } \\
\text { 樹枝状, 黒 }\end{array}$ \\
\hline $\mathrm{ZnCl}_{2}$ & Sat. & $\begin{array}{l}13.0 \\
38.0\end{array}$ & $\begin{array}{l}2.3 \\
3.0\end{array}$ & $\begin{array}{l}\text { 樹枝状, 黒 } \\
\text { 樹枝状, 黒 }\end{array}$ \\
\hline $\mathrm{BiCl}_{3}$ & 0.32 & $\begin{array}{l}0.64 \\
6.4\end{array}$ & $\begin{array}{l}5.0 \\
7.0\end{array}$ & $\begin{array}{l}\text { こけ状, 黒 } \\
\text { こけ状, 黒 }\end{array}$ \\
\hline $\mathrm{H}_{2} \mathrm{PtCl}_{6}$ & Sat. & 13.0 & 300 & コロイド状 \\
\hline
\end{tabular}




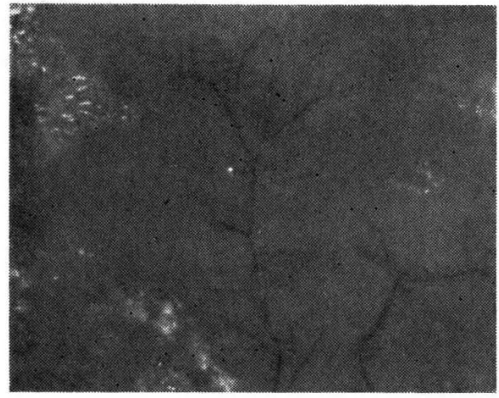

(a) 電流密度 $13 \mathrm{~mA} / \mathrm{cm}^{2}$ 電解時間 $150 \mathrm{~s}$ $\times 140$

军真 1 鉛の樹枝状析出（電流密度の増大とともに針状となる） 電解時間 $30 \mathrm{~s}$

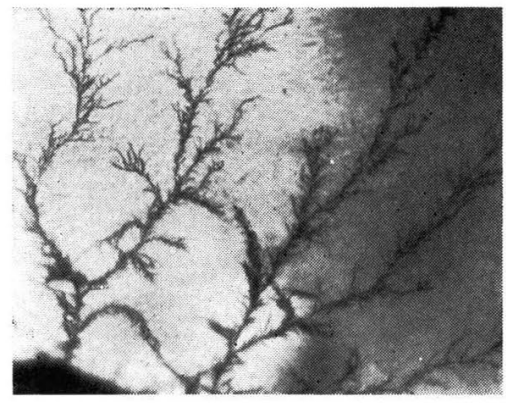

(b) 電流密度 $6.4 \mathrm{~mA} / \mathrm{cm}^{2} \quad \times 140$

(電解浴 $\mathrm{Pb}\left(\mathrm{NO}_{3}\right)_{2} 1 \mathrm{~g} / 100 \mathrm{~m} l$ DMF)

が，DMF- $\mathrm{NiCl}_{2}$ 溶液の場合には $0.013 \sim 0.025 \mathrm{~A} / \mathrm{cm}^{2}$ の電流密度ですでに樹枝状析出となる注 ${ }^{3}$ (写真 2 )。= ッケル電析の場合はとくに電流密度が $25 \mathrm{~mA} / \mathrm{cm}^{2}$ 以上 では浴電圧は $20 \mathrm{~V}$ にも達し, かつ電圧が微細な振動を 注 3 ） $\mathrm{DMSO}$ - $\mathrm{NiCl}_{2}$ の場合 $0.02 \sim 0.04 \mathrm{~A} / \mathrm{cm}^{2}$ の電流 密度で樹枝状析出になった
示す。このときカソード表面からはガスの発生が認めら れたので, この振動はガス発生による表面層のかくらん によるものであることがわかる。

これに反してコバルトの場合は, 電流密度が $25 \mathrm{~mA} /$ $\mathrm{cm}^{2}$ になっても浴電圧は数ボルトで振動もみられない ので, ガスの発生は起こっていないことがわかる。

第 4 表電析物の X 線解析結果のデータ

\begin{tabular}{|c|c|c|c|c|c|c|c|c|c|}
\hline \multirow{2}{*}{ 物 質 } & \multirow{2}{*}{$\frac{\text { 実験値 }}{\mathrm{d} \AA}$} & \multicolumn{3}{|c|}{ A S TMカード } & \multirow{2}{*}{ 物 質 } & \multirow{2}{*}{$\frac{\text { 実験値 }}{\text { d } \AA}$} & \multicolumn{3}{|c|}{ A S TMカード } \\
\hline & & d $\AA$ & I/Io & $\mathrm{hK} l$ & & & d $\AA$ & $\mathrm{I} / \mathrm{I}_{\mathrm{O}}$ & $\mathrm{hK} l$ \\
\hline \multirow{3}{*}{$\mathrm{Ni}$} & 2. 032 & 2. 034 & 100 & 111 & \multirow{5}{*}{$\mathrm{Bi}$} & 1.866 & 1.868 & 23 & 022 \\
\hline & 1.759 & 1. 762 & 42 & 200 & & 1.639 & 1.639 & 9 & 204 \\
\hline & 1.241 & 1.246 & 21 & 220 & & 1.556 & 1.556 & 6 & 017 \\
\hline \multirow{3}{*}{$\mathrm{Pd}$} & 2. 259 & 2. 246 & 100 & 111 & & 1.491 & 1.491 & 13 & 116 \\
\hline & 1.953 & 1.945 & 42 & 200 & & 1.443 & 1.443 & 16 & 212 \\
\hline & 1.384 & 1.378 & 25 & 220 & \multirow{4}{*}{$\mathrm{Cu}$} & 2.475 & 2.465 & 100 & $111^{*}$ \\
\hline \multirow{7}{*}{$\mathrm{Pb}$} & 2.822 & 2. 856 & 100 & 111 & & 2. 085 & 2. 088 & 100 & 111 \\
\hline & 2. 462 & 2. 462 & 50 & 200 & & 1.804 & 1.808 & 46 & 200 \\
\hline & 1.743 & 1.750 & 31 & 220 & & 1.277 & 1.278 & 20 & 220 \\
\hline & 1.486 & 1.493 & 32 & 311 & \multirow{6}{*}{$\mathrm{Zn}$} & 2.475 & 2. 473 & 53 & 002 \\
\hline & 1.425 & 1. 429 & 9 & 222 & & 2.315 & 2. 308 & 40 & 100 \\
\hline & 1.230 & 1. 238 & 2 & 400 & & 2. 099 & 2.091 & 100 & 101 \\
\hline & 1.134 & 1.136 & 10 & 331 & & 1.687 & 1.687 & 28 & 102 \\
\hline \multirow{5}{*}{$\mathrm{Ag}$} & 2. 365 & 2. 359 & 100 & 111 & & 1.342 & 1.342 & 25 & 103 \\
\hline & 2.045 & 2.044 & 40 & 200 & & 1.334 & 1.332 & 21 & 110 \\
\hline & 1.445 & 1.445 & 25 & 220 & \multirow{8}{*}{$\mathrm{Cd}$} & 2. 805 & 2. 809 & 65 & 002 \\
\hline & 1.233 & 1.231 & 26 & 311 & & 2.578 & 2.580 & 32 & 100 \\
\hline & 1. 179 & 1. 179 & 12 & 222 & & 2.344 & 2. 345 & 100 & 101 \\
\hline \multirow{5}{*}{$\mathrm{Bi}$} & 3. 290 & 3.28 & 100 & 102 & & 1.903 & 1.901 & 32 & 102 \\
\hline & 2.368 & 2.39 & 40 & 014 & & 1.514 & 1.516 & 26 & 103 \\
\hline & 2. 270 & 2. 273 & 41 & 110 & & 1.488 & 1.490 & 19 & 110 \\
\hline & 2. 032 & 2.030 & 8 & 105 & & 1.316 & 1.316 & 17 & 112 \\
\hline & 1.969 & 1.970 & 10 & 113 & & 1.255 & 1.258 & 13 & 201 \\
\hline
\end{tabular}




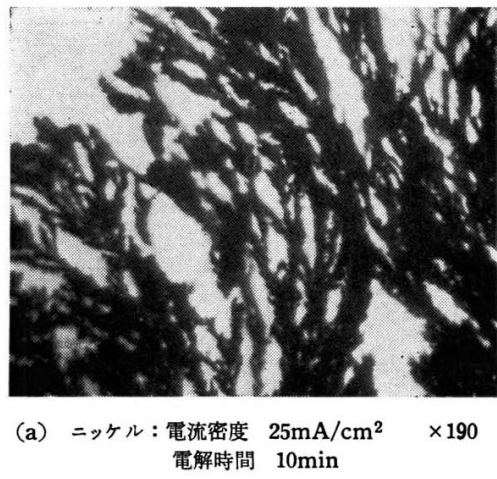

写真 2 ニッケル，コバルトの樹枝状析出

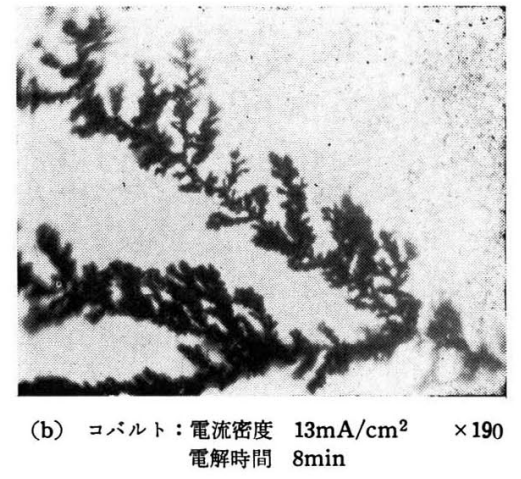

亜鉛，鉛，銀の場合には浴電圧は低く，良く発達した デンドライトになったが，鉛は幹と枝との角度が直角を なす $3 \mathrm{D}$ (100) 型であり，銀は $45^{\circ}$ で $3 \mathrm{D}$ (110) 型 である ${ }^{10)}$ 。これはX線解析により確認された(第 4 表)。 覀鉛の析出は明確な角度を示さない。

次にコロイド状析出物が得られた白金であるが，この 場合浴電圧は数 $100 \mathrm{~V}$ にも達し, ガス発生を伴う。析出物 は黒色でその中に系状のものも含まれていたが，X線解 析の結果は無定形で白金の確証は得られなかった。扣そ らく白金黒のような微細結晶に溶媒である D M F が吸着 されていたのであろう。

(3)化属するものは電解条件によって平滑についたり, 樹枝状に発達するもので, ビスマスは $6.4 \mathrm{~mA} / \mathrm{cm}^{2}$ 以 下の電流密度では形のきれいな樹枝状析出物は得られ ず, 析出物は電極表面にこけ状に付着した。ガスの発生 はない。

しかし $6.4 \mathrm{~mA} / \mathrm{cm}^{2}$ 以上の電流密度では樹枝状に発 達したが電流を切断するとますなくこけ状に変化した。

パラジゥムと銅は浴電圧がかなり高く, 高電流密度 $\left(13 \mathrm{~mA} / \mathrm{cm}^{2}\right)$ では粉末状析出となる。銅電析物の $\mathrm{X}$ 線 解析の結果, $\mathrm{Cu}_{2} \mathrm{O}$ の存在も認められたが, これは DM $\mathrm{F}$ 中に微量に存在していた水分または溶存酸素によるる のか，またはX線解析の試料作成中にできたるのかは明 らかでない。

カドミウムも $25 \mathrm{~mA} / \mathrm{cm}^{2}$ の高電流密度範囲ではスポ ンジ状の析出となり, 同時にガス発生を伴う。しかし低

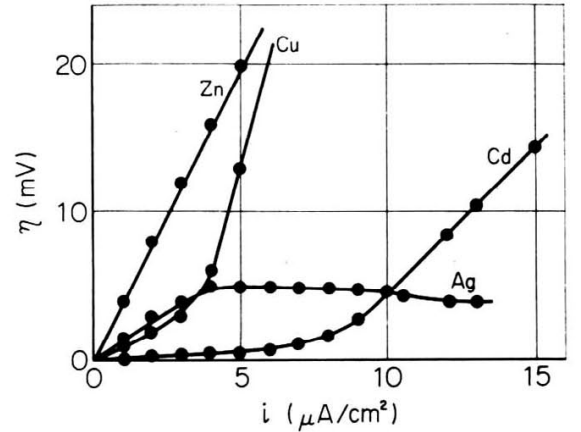

第4図金属の陰分極曲線

電流密度 (2.6 mA/ $\left.\mathrm{cm}^{2}\right)$ においては, 樹枝状析出でガ スの発生は認められない。さらに低い電流密度 (0.64 $\mathrm{mA} / \mathrm{cm}^{2}$ ) ではこけ状析出となる。

\section{3-3 分極の測定}

分極の測定結果は 第 4 図 に示されている。この実験 においては電解液の組成は $0.1 \mathrm{~mol}$ の金属塩と, 電導 度を増すために支持電解質として $0.1 \mathrm{~mol}$ の $\mathrm{NaClO}_{4}$ を加えたものである。

一般に過電圧が大きい金属は均一電着性が良く，逆に 小さいものは均一電着性が悪いとされているが, 分極の 測定結果から同じ電流密度に拈ける過電圧の大きさを比 較すると，亜鉛と銅は過電圧が大きく，カドミウムと銀 とは過電圧が小さい。過電圧の値が 0 に近い直線部分の かたむきから系の交換電流密度を次式により求めてみる

第 5 表 DMF と水溶液中での交換電流密度の比較

\begin{tabular}{|c|c|c|c|c|}
\hline 金属 & $\mathrm{i}_{0} \mathrm{~A} / \mathrm{cm}^{2}$ & 定 液 (DMF) & $\mathrm{i}_{0} \mathrm{~A} / \mathrm{cm}^{2}$ & 液 $\left(\mathrm{H}_{2} \mathrm{O}\right)$ \\
\hline $\mathrm{Zn}$ & $3.2 \times 10^{-6}$ & $0.1 \mathrm{M} \mathrm{ZnCl}+0.1 \mathrm{M} \mathrm{NaClO} 4$ & $7 \times 10^{-4}$ & $10^{-3} \mathrm{M} \mathrm{Zn}\left(\mathrm{NO}_{3}\right)_{2}+1 \mathrm{M} \mathrm{KNO}_{3}$ \\
\hline $\mathrm{Cu}$ & $1.0 \times 10^{-5}$ & $0.1 \mathrm{M} \mathrm{CuSO}_{4}+0.1 \mathrm{M} \mathrm{NaClO}$ & $2 \times 10^{-5}$ & $1 \mathrm{M} \mathrm{CuSO}_{4}$ \\
\hline $\mathrm{Cd}$ & $9.0 \times 10^{-5}$ & $0.1 \mathrm{M} \mathrm{CdCl}{ }_{2} \cdot 2 \mathrm{DMF}+0.1 \mathrm{M} \mathrm{NaClO}{ }_{4}$ & $1.2 \times 10^{-1}$ & $10^{-3} \mathrm{M} \mathrm{Cd}\left(\mathrm{NO}_{3}\right)_{2}+1 \mathrm{M} \mathrm{KNO}_{3}$ \\
\hline Pd & $1.2 \times 10^{-6}$ & $0.1 \mathrm{M} \mathrm{PdCl}{ }_{2}+0.1 \mathrm{M} \mathrm{NaClO}$ & $>2 \times 10^{-1}$ & $10^{-3} \mathrm{M} \mathrm{Pd}\left(\mathrm{NO}_{3}\right)_{2}+1 \mathrm{M} \mathrm{KNO}_{3}$ \\
\hline $\mathrm{Ag}$ & 1. $1 \times 10^{-5}$ & $0.1 \mathrm{M} \mathrm{AgNO}_{3}+0.1 \mathrm{M} \mathrm{NaClO}$ & 1. $1 \times 10^{-2}$ & $10 \mathrm{~g} / 100 \mathrm{~g} \mathrm{AgNO}_{3}$ \\
\hline
\end{tabular}


と，第 5 表のようになる。

$$
i_{0}=\frac{R T}{z F} \cdot\left(\frac{\partial \eta}{\partial i}\right)_{\eta \rightarrow 0}^{-1}
$$

この值を水溶液系での各金属についての既知の值と比 較してみると ${ }^{11)}$ ，銅を除いては水溶液系の場合よりかな り小さいので，したがって過電圧は大きいわけである。 樹枝状析出は過電圧の小さい金属が拡散律速になったと き性じるといわれているので'2),13)，この非水 DMF 溶液の場合は過電圧が高いということは樹枝状析出が起 こりにくいことを意味している。しかし一方溶液中の金 属イオン濃度は低い $(0.1 \mathrm{~mol} く ら い)$ ので, 拡散律速 になる電流密度は低いところにある。さらに電導度の測 定結果から D M F 中に解離している金属イオン濃度は非 常に小さいので, 抬散してくる化学種はほとんぞ中性分 子(たとえば $\mathrm{NiCl}_{2}$ )であって，これが電極近傍において 解離し電極反応を起こすと考えられる。水溶液系では限 界電流密度に近い条件で電解する場合, 同時に水素ガス の発生が伴らが，このDMFにはカソードで反応する活 性水素がないので水素ガスの発生は起こらない。水素ガ スの発生は金属の析出を粉末状をたはスポンジ状にする ので, この水素の発生がないことは樹枝状析出を起こり やすくする。いいかえると高電流密度で樹枝状析出が起 こる条件であっても，もし水素ガスの発生を伴らと発 生ガスのかくらん作用のために金属の結晶成長が阻害さ れ, 溶液側の層状の払散層の構造も変化する。事実水溶 液系からのニッケル，コバルト，鉄などの樹枝状析出の 場合でも，著しい高電流密度であるにもかかわらず，水 素ガス発生は全〈ないことが知られている7》,8〉。

\section{4. 総括}

銀, ビスマス, カドミウム, コバルト, 銅, ニッケル， 鉛, パラジウム, 白金, 亜鉛の 10 種類の金属塩を非水 D MF溶媒に溶解し，金属のカソード析出形態を顕微鏡的 観察により研究した。これをまとめると

(1) これらの金属のらち銀, コバルト, ニッケル, 鉛, 亜鉛は常に結晶性の樹枝析出形態を示す。とくにコ バルトとニッケルは水溶液系に比べて低い電流密度にお いて樹枝状析出となる。
（2）白金はコロイド状析出となり，X線的には無定形 である。

(3) ビスマス，カドミウム，銅，パラジウムは電流密 度によって樹枝状になったり、紛末状またはスポンジ状 になる。

（4）金属析出の交換電流密度は銅を除いては水溶液の 場合より小さく，過電圧は高い。

(5) 樹枝状析出を支配する因子には水素発生の有無が 関係している。このDMFには水溶液系の場合のような 水素ガスの発生がないので，金属の電析形態を調べるに は適していると思われる。

謝辞

本研究に対し溶媒のDMFを提供された日東化学工業 株式会社（東京）に感謝します。（1970-12-15受理）

\section{文献}

1) H. Röhler, Z. Elektrochem., 16, 416 (1910)

2) L.F. Yntena and L.F. Audrieth, J. Am. Chem. Soc., 52, 2693 (1930)

3) A. Brenner, J. Electrochem. Soc., 103, 652 (1956), H. Conner and A. Brenner, ibid., 103, 657 (1956), G.B. Wood and A. Brenner, ibid., 104, 29 (1957)

4) 林 忠夫, 石田武男, 電気化学, 30，552（1962）

5) 林 忠夫, 電気化学, 33，535，604 (1965)

6) A.B. Thomas and C.A. Vincent, J. Electrochem. Soc., 79, 1843 (1957)

7) 田島 栄, 尾形幹夫, 電気化学, 37, 179 (1969)

8 ）尾形幹夫, 田島 栄, ibid., 37, 724 (1969)

9) S. Morisaki, N. Baba and S. Tajima, Denki Kagaku, 38, 746 (1970)

10）菊池 実, 電気化学, 24，431（1956）

11) N. Tanaka and R. Tamamushi, Electrochim. Acta, 9, 963 (1964)

12) G. Wranglén, Electrochim. Acta, 2, 130 (1955)

13) G. Wranglén, J. Electrochem. Soc., 97, 353 (1950) 